\title{
Diet or exercise, or both, for weight reduction in women after childbirth (Review)
}

\author{
Amorim Adegboye AR, Linne YM, Lourenco PMC
}

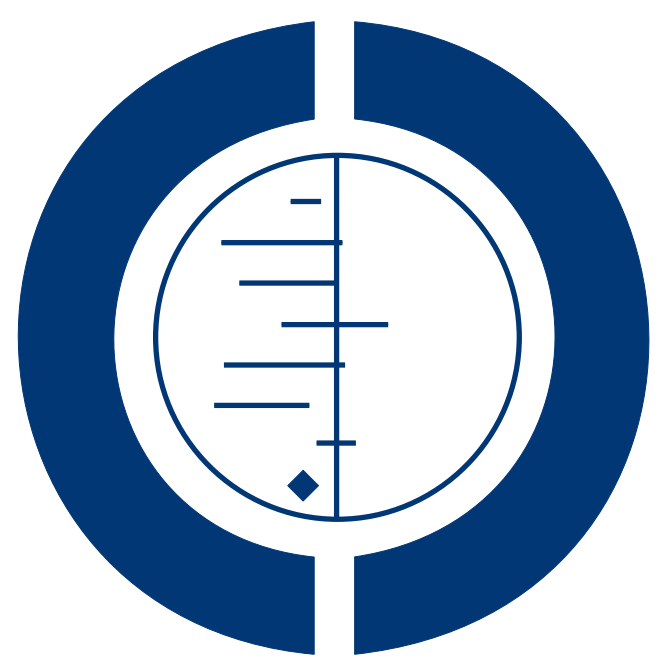

\section{THE COCHRANE COLLABORATION $^{\circledR}$}

This is a reprint of a Cochrane review, prepared and maintained by The Cochrane Collaboration and published in The Cochrane Library 2007, Issue 3

http://www.thecochranelibrary.com

\section{WILEY}

Diet or exercise, or both, for weight reduction in women after childbirth (Review)

Copyright $\odot 2012$ The Cochrane Collaboration. Published by John Wiley \& Sons, Ltd. 
TABLE OF CONTENTS

HEADER . . . . . . . . . . . . . . . . . . . . . . . . . . . . . . . . . . . . 1

ABSTRACT . . . . . . . . . . . . . . . . . . . . . . . . . . . . . . . . . . . . . . . . . . . . . . .

PLAIN LANGUAGE SUMMARY . . . . . . . . . . . . . . . . . . . . . . . . . . . . . . . . . . . 2

BACKGROUND . . . . . . . . . . . . . . . . . . . . . . . . . . . . . . . . . . . . . . . . .

OBJECTIVES . . . . . . . . . . . . . . . . . . . . . . . . . . . . . . . . . . . . . . . $4 \begin{gathered}4 \\ \text { O }\end{gathered}$

METHODS . . . . . . . . . . . . . . . . . . . . . . . . . . . . . . . . . . . . . . . .

RESULTS . . . . . . . . . . . . . . . . . . . . . . . . . . . . . . . . . . . . . . . 7

DISCUSSION . . . . . . . . . . . . . . . . . . . . . . . . . . . . . . . . . . . . . 9

AUTHORS' CONCLUSIONS . . . . . . . . . . . . . . . . . . . . . . . . . . . . . . . . . . . . . . . .

ACKNOWLEDGEMENTS . . . . . . . . . . . . . . . . . . . . . . . . . . . . . . . . . 11

REFERENCES . . . . . . . . . . . . . . . . . . . . . . . . . . . . . . . . . . . . . . 11

CHARACTERISTICS OF STUDIES . . . . . . . . . . . . . . . . . . . . . . . . . . . . . . . . . . . . . 15

DATA AND ANALYSES . . . . . . . . . . . . . . . . . . . . . . . . . . . . . . . . . . . . . . . . . .

Diet or exercise, or both, for weight reduction in women after childbirth (Review)

Copyright $\odot 2012$ The Cochrane Collaboration. Published by John Wiley \& Sons, Ltd. 


\title{
[Intervention Review] \\ Diet or exercise, or both, for weight reduction in women after childbirth
}

\author{
Amanda R Amorim Adegboye ${ }^{1}$, Yvonne M Linne ${ }^{2}$, Paulo Mauricio C Lourenco ${ }^{3}$ \\ ${ }^{1}$ Research Unit for Dietary Studies, Institute of Preventive Medicine, Copenhagen University Hospital, Copenhagen, Denmark. \\ ${ }^{2}$ Obesity Unit, Karolinska University Hospital, Stockholm, Sweden. ${ }^{3}$ Department of Epidemiology, University of State of Rio de \\ Janeiro, Rio de Janeiro, Brazil
}

Contact address: Amanda R Amorim Adegboye, Research Unit for Dietary Studies, Institute of Preventive Medicine, Copenhagen University Hospital, Øster Søgade 18, Copenhagen, DK-1357, Denmark. aar@ipm.regionh.dk.

Editorial group: Cochrane Pregnancy and Childbirth Group.

Publication status and date: Edited (no change to conclusions), published in Issue 2, 2012.

Review content assessed as up-to-date: 23 April 2007.

Citation: Amorim Adegboye AR, Linne YM, Lourenco PMC. Diet or exercise, or both, for weight reduction in women after childbirth. Cochrane Database of Systematic Reviews 2007, Issue 3. Art. No.: CD005627. DOI: 10.1002/14651858.CD005627.pub2.

Copyright (C) 2012 The Cochrane Collaboration. Published by John Wiley \& Sons, Ltd.

\begin{abstract}
A B S T R A C T
Background

Weight retention after pregnancy may contribute to obesity. It is known that diet and exercise are recommended components of any weight loss programme in the general population. However, strategies to achieve healthy body weight among postpartum women have not been adequately evaluated.
\end{abstract}

\section{Objectives}

The objectives of this review were to evaluate the effect of diet, exercise or both for weight reduction in women after childbirth, and to assess the impact of these interventions on maternal body composition, cardiorespiratory fitness, breastfeeding performance and other child and maternal outcomes.

\section{Search methods}

We searched the Cochrane Pregnancy and Childbirth Group's Trials Register (September 2006) and LILACS. We scanned secondary references and contacted experts in the field. We updated this search on 5 December 2011 and added the results to the awaiting classification section.

\section{Selection criteria}

All published and unpublished randomised controlled trials (RCT) and quasi-randomised trials of diet or exercise or both, among women during the postpartum period.

\section{Data collection and analysis}

Three review authors independently assessed trial quality and extracted data. Results are presented using risk ratio for categorical data and mean difference (MD) for continuous data. Data were analysed with a fixed-effect model. A random-effects model was used in the presence of heterogeneity.

Diet or exercise, or both, for weight reduction in women after childbirth (Review)

Copyright $\odot 2012$ The Cochrane Collaboration. Published by John Wiley \& Sons, Ltd. 


\section{Main results}

Six trials involving 245 women were included. Women who exercised did not lose significantly more weight than women in the usual care group (one trial; $\mathrm{n}=33$; MD $0.00 \mathrm{~kg}$; $95 \%$ confidence interval (CI) -8.63 to 8.63). Women who took part in a diet (one trial; $\mathrm{n}=$ 45; MD -1.70 kg; 95\% CI -2.08 to -1.32), or diet plus exercise programme (four trials; $\mathrm{n}=169$; MD $-2.89 \mathrm{~kg}$; $95 \%$ CI -4.83 to -0.95 ), lost significantly more weight than women in the usual care. There was no difference in the magnitude of weight loss between diet and diet plus exercise group (one trial; $\mathrm{n}=43$; MD $0.30 \mathrm{~kg}$; $95 \%$ CI -0.60 to 0.66 ). The interventions seemed not to affect breastfeeding performance adversely.

\section{Authors' conclusions}

Preliminary evidence from this review suggests that both diet and exercise together and diet alone help women to lose weight after childbirth. Nevertheless, it may be preferable to lose weight through a combination of diet and exercise as this improves maternal cardiorespiratory fitness and preserves fat-free mass, while diet alone reduces fat-free mass. This needs confirmation in large trials. For women who are breastfeeding, more evidence is required to confirm whether diet or exercise, or both, is not detrimental for either mother or baby.

[Note: The 23 citations in the awaiting classification section of the review may alter the conclusions of the review once assessed.]

\section{PLAIN LANGUAGE SUMMARY}

\section{Diet or exercise, or both, for weight reduction in women carrying excess weight after childbirth}

Women naturally gain weight during pregnancy and many gradually lose it afterwards. Some women, though, find it difficult to lose the pregnancy-related weight during postpartum and there is concern that this may be a health risk. The retention of weight gained during pregnancy may contribute to obesity. Obesity in the general population increases the risk of diabetes, heart disease and high blood pressure. It is suggested that women who return to their prepregnancy weight by about six months have a lower risk of being overweight 10 years later. The review looked for studies to assess the impact of dieting or exercise, or both, on women's weight loss in the months after giving birth. It paid particular attention to breastfeeding women to be sure that breastfeeding was not compromised. The review of trials found six studies involving only 245 women. Preliminary findings suggest that diet combined with exercise or diet alone compared to usual care seemed to enhance weight loss during postpartum. Thus, there is potential for this to play a role in preventing future maternal obesity. However, there was insufficient evidence to be sure and a lack of sufficient data for women who are breastfeeding. In addition, it seems preferable to lose weight through a combination of dieting and exercise to dieting alone because exercise is thought to improve circulation and heart fitness, and to preserve lean body mass. Further research is needed.

\section{B A C K G ROU N D}

\section{Obesity related to childbearing}

There is evidence suggesting that retention of weight gained during pregnancy contributes to female overweight and obesity (Gore 2003; Linne 2002; Linne 2003a; Rooney 2002). In women, being overweight or obese substantially raises the risk of serious dietrelated chronic disorders, including diabetes mellitus, heart disease and hypertension (Linne 2004; Manson 1990).

\section{Postpartum weight retention}

The weight retained after pregnancy is defined as the difference between postpartum and prepregnancy weight (IOM 1990). The Health Sciences Descriptor of Virtual Health Library states that postpartum or puerperium is "a period from delivery of the placenta until return of the reproductive organs to their normal nonpregnant morphologic state. In humans, the puerperium generally lasts for six to eight weeks" (DeCs 2004). However, it is recommended to increase the definition of the postpartum period to one year, because many physiologic changes due to pregnancy remain up to one year after childbirth, such as the duration of breastfeeding (Mottola 2002). 
Despite growing concern about weight-related problems among postpartum women, neither a cut-off point defining excess weight retention after childbirth, nor an ideal time to return to prepregnancy weight has been established in the literature. Linne et al carried out a study, which aimed to examine long-term weight development after pregnancy in a 15 -year follow-up study. The authors found that by six months postpartum, $56.3 \%$ of women who did not become overweight at 15 -year follow-up had returned to within $1.5 \mathrm{~kg}$ of their prepregnancy weight, compared to $27.7 \%$ of whom became overweight. By one year, these figures had risen to $60.4 \%$ in the non-overweight women and only $34.6 \%$ in the overweight group (Linne 2003b). Rooney and Schauberger reported that women who lost all pregnancy weight by six months postpartum, regardless of breastfeeding status, were only $2.4 \mathrm{~kg}$ heavier 10 years after childbirth, while women who retained postpartum weight were $8.3 \mathrm{~kg}$ heavier at 10 -year follow-up. The authors argued that failure to lose pregnancy weight by six months postpartum is considered an important predictor of long-term obesity. Although it seems beneficial that women return to pregestational weight by six months after childbirth, only $37 \%$ of women were able to lose the weight gained during pregnancy at this point (Rooney 2002). Studies estimated that, about one year after childbirth, women may retain 0.5 to $4.0 \mathrm{~kg}$ on average (AbuSabha 1998; Keppel 1993; Linne 2002; Linne 2003c; Ohlin 1990; Olson 2003). The average amount of weight retained as a result of pregnancy is relatively small; however, there is a subset of women that seems to be at greater risk of gaining significant amounts of weight with childbearing (Rossner 1992; Rossner 1995). In longitudinal studies, the proportion of women retaining $4.5 \mathrm{~kg}$ or more during postpartum ranges from $14 \%$ to $25 \%$ (Greene 1988; Olson 2003; Rossner 1995; Schauberger 1992). Women who retain a considerable amount of weight after delivery have a higher risk of doing so in subsequent gestations (Linne 2003c).

Postpartum weight retention might be determined by many factors, including low socio-economic status, parity and high prepregnancy body mass index (BMI) (Crowell 1995; Schauberger 1992). However, excessive weight gain during pregnancy is the strongest predictor of postpartum weight retention. Various studies showed that the greater the gestational weight gain, the greater the postpartum weight retention (Gunderson 1999; Kac 2003; Linne 2003c; Rossner 1995). According to Olson et al, lower income women who gain more weight in pregnancy than the Institute of Medicine (IOM) recommends are at high risk for major gain with childbearing (Olson 2003). Apart from that, the postpartum period might be related to an increase in food intake and a decrease in physical activity (Clark 1999; Sadurkis 1988; Symons Downs 2004). Consequently, it is considered a vulnerable period for gaining weight (Leermakers 1998). Thus, although gestational weight gain has a strong correlation with postpartum weight retention, gaining additional weight after delivery may also have a significant role in maternal obesity (Greene 1988).

\section{Returning to prepregnancy weight}

Although it is expected that breastfeeding women lose weight gradually, findings related to breastfeeding and postpartum weight loss are inconsistent (Crowell 1995; Schauberger 1992). Decline in physical activity and increase in caloric intake above the ordinary demand of lactation may explain why some breastfeeding women fail to return to prepregnancy weight. It is argued that Recommended Dietary Allowance (RDA) for breastfeeding women is too high, and the need for increased calories for milk production may be offset by the reduction in physical activity and basal metabolic rate in breastfeeding women (Crowell 1995).

Since behavioural change may also explain why some women fail to lose pregnancy-related weight or gain additional weight, or both, in the first postpartum year (Olson 2003; Schauberger 1992), postpartum weight loss seems to be a critical issue for women who were overweight or obese before pregnancy. However, help strategies for returning to prepregnancy weight are also important for normal-weight women who gained excessive weight during pregnancy.

Crowell highlights that a period of at least six months postpartum is necessary to facilitate weight loss with the purpose of helping women to return to prepregnancy weight without posing any risk to maternal and child health (Crowell 1995). Even though the IOM states that gradual weight loss during lactation $(0.5 \mathrm{~kg} /$ week $)$ appears safe for overweight women (IOM 1991), the best strategy in achieving postpartum weight reduction and the effect of high weight loss rate has not been critically evaluated.

It is known that diet and exercise impose energy deficit, therefore they are recommended components of any weight loss programme in the general population (WHO 1998). Nonetheless, the effects of negative energy balance during the postpartum period, achieved by energy restriction intake, increased energy expenditure or the combination of both are still not fully understood. Since the growth rate of exclusively breastfed infants depends on the energy provided by maternal breastmilk, it is paramount to assess the impact of diet and exercise on lactation performance (Wood 2004).

\section{Diet and exercise among breastfeeding women}

Observational studies demonstrated that long-term and severe under-nutrition was associated with milk volume reduction and lower nutrient concentration, whereas mild under-nourishment had a weak correlation with change in milk volume and composition. These results suggest that when food intake is limited for a short period of time, maternal prolactin concentration level increases, which appears to ensure milk production (Coward 1984; Prentice 1994). However, the findings of dietary intervention studies are controversial. While some studies suggested that a calorie-restricted diet had no impact on milk quantity and quality

Diet or exercise, or both, for weight reduction in women after childbirth (Review) 
(Dusdieker 1994; McCrory 1999), other research reported that well-nourished mothers who had consumed less than $1500 \mathrm{kcal} /$ day experienced a decrease in milk volume and put the growth rate of their babies at risk (Strode 1986).

Likewise, the effect of exercise during postpartum in relation to lactation performance is still a contentious issue. Some trials, including exclusively breastfeeding mothers, indicated that exercise performed during postpartum had no adverse effect on lactation (Dewey 1994b; Lovelady 1995). Nevertheless, another study aimed to observe the infant acceptance of postexercise breastmilk demonstrated a significant difference in acceptance of pre-exercise and postexercise milk. Women had a significant increase in lactic acid level in breastmilk collected at 10 minutes and 30 minutes after the exercise period. The increase in lactic acid level might affect milk palatability, making it have a sour taste that babies disliked. Furthermore, the lactic acid may have a degradative effect on milk immunoglobulin A concentration (Wallace 1992b), an important factor which confers protection against most infectious agents (Mestecky 1986).

Apart from the effect of postpartum weight loss programmes on lactation performance, it is important to examine the changes in maternal body composition imposed by different intervention strategies. It is desirable that women reduce the percentage of body fat and increase or preserve their lean mass during the intervention programme (Wood 2004). In order to identify which intervention optimises weight loss and fat reduction, while preserving or enhancing fat-free mass, the results of some experimental studies should be pooled in a systematic manner.

The diversity in magnitude of weight loss, body composition and effects on lactation performance found in the literature may be as a result of different study designs, selection criteria of control groups, sample sizes, type of participants and intervention strategies, duration of follow up, dropout rates and quality of weight measurements. Before the results of such studies can be applied in a clinical setting by healthcare professionals to determine an appropriated prescription of diet or exercise, or both, for postpartum women, these data must be selected using high-quality criteria and summarised in an objective fashion.

\section{O B J E C T IVES}

The primary objective of this review was to evaluate the effect of diet, exercise or both for weight reduction in women carrying excess weight after childbirth. Secondary objectives were to examine the impact of these interventions on maternal body composition; breastfeeding performance; cardiorespiratory fitness; infant weight gain and growth; and other child and maternal outcomes.

\section{METHODS}

\section{Criteria for considering studies for this review}

\section{Types of studies}

We considered for inclusion randomised controlled trials and quasi-randomised trials of diet or exercise or both, with a concurrent comparison group, in women during the postpartum period.

\section{Types of participants}

To be eligible, studies must have included women recruited to the intervention programme up to 12 months after childbirth. The participants were women who had given birth to a singleton healthy term infant; were aged at least 18 years; and were overweight or obese, or had gained excessive weight during pregnancy, or both. Normal-weight women were eligible if, during pregnancy, they had gained weight above the IOM's recommendations or whose current weight had significantly exceeded their prepregnancy weight. Women who were underweight before pregnancy were not included. Participants were required to not be taking any medication that significantly interfered with body weight. There was no restriction in relation to maternal breastfeeding status.

\section{Types of interventions}

We considered interventions in postpartum women involving diet or exercise, or both.

The nutritional interventions included in this review were:

(a) dietary advice intended to produce weight reduction delivered through group meetings, by telephone calls or by mail correspondence;

(b) individualised dietary counselling;

(c) prescription of a calorie-restricted diet.

Exercise interventions included in this review were:

(a) any type of exercise counselling that encouraged women to engage in regular recreational exercises (for example, walking, jogging, sports) in order to promote weight loss or improve physical fitness;

(b) structured exercise programmes, in which women participated in supervised exercise sessions.

We did not consider training programmes with exercise for preventing or treating pelvic or back pain and urinary incontinence. We included trials in which the stated objectives were not weight loss only if they involved one of the interventions mentioned above and assessed at least one relevant outcome measure.

There was no restriction concerning who delivered the interventions. Type, intensity, frequency, duration and timing (postpartum period at beginning and end) of the interventions varied between studies. Trial duration was defined according to the numbers of months over which each was conducted: short term (less than three months), medium term (from three to six months) and long term (longer than six months). Frequency, intensity, duration

Diet or exercise, or both, for weight reduction in women after childbirth (Review)

Copyright $\odot 2012$ The Cochrane Collaboration. Published by John Wiley \& Sons, Ltd. 
and timing of the intervention were extracted from the reports and described in the Characteristics of included studies table. We did not consider any type of intervention in combination with medication in this review.

\section{Comparisons}

- Diet versus usual care;

- exercise versus usual care;

- diet plus exercise versus usual care;

- diet versus exercise;

- diet plus exercise versus exercise alone;

- diet plus exercise versus diet alone.

\section{Types of outcome measures}

\section{Primary outcomes}

\section{Primary outcomes}

- Change in body weight $(\mathrm{kg})$, defined as body weight at the end minus body weight at the beginning of study (negative change implies postpartum weight loss);

- percentage of women who returned to prepregnancy weight or lost weight retained after childbirth;

- percentage of women who achieved healthy weight, according to WHO 1998 definitions (based on BMI classification).

\section{Secondary outcomes}

- Change in percentage of body fat (\%);

- change in fat-free mass $(\mathrm{kg})$;

- change in cardiorespiratory fitness $\left(\mathrm{VO}_{2} \mathrm{max}, \mathrm{mL} / \mathrm{kg} /\right.$ minute);

- change in basal plasma prolactin concentration $(\mu \mathrm{g} / \mathrm{mL})$;

- change in milk volume (g/day);

- milk immunoglobulin (Ig) A concentration $(\mu \mathrm{g} / \mathrm{mL})$;

- number of mothers who stop breastfeeding;

- duration of breastfeeding (exclusive or predominant,

according to WHO 1991 definitions);

- infant length gain $(\mathrm{cm})$;

- infant weight gain (g);

- maternal morbidity (for example, anaemia, readmission to hospital);

- adverse events (for example, exercise-induced injuries, side effects of very low-calorie diets);

- maternal satisfaction with interventions;

- compliance with interventions.

We gathered information on outcome measures related to milk volume, plasma prolactin concentration and infant length and weight gain only from trials which included exclusively lactating women.

\section{Search methods for identification of studies}

\section{Electronic searches}

We searched the Cochrane Pregnancy and Childbirth Group's Trials Register by contacting the Trials Search Co-ordinator (September 2006). We updated the search of the Cochrane Pregnancy and Childbirth Group's Trials Register on 5 December 2011 and added the results to Studies awaiting classification.

The Cochrane Pregnancy and Childbirth Group's Trials Register is maintained by the Trials Search Co-ordinator and contains trials identified from:

1. quarterly searches of the Cochrane Central Register of Controlled Trials (CENTRAL);

2. weekly searches of MEDLINE;

3. weekly searches of EMBASE;

4. handsearches of 30 journals and the proceedings of major conferences;

5. weekly current awareness alerts for a further 44 journals plus monthly BioMed Central email alerts.

Details of the search strategies for CENTRAL, MEDLINE and EMBASE, the list of handsearched journals and conference proceedings, and the list of journals reviewed via the current awareness service can be found in the 'Specialized Register' section within the editorial information about the Cochrane Pregnancy and Childbirth Group.

Trials identified through the searching activities described above are each assigned to a review topic (or topics). The Trials Search Co-ordinator searches the register for each review using the topic list rather than keywords.

In addition, we searched LILACS (1983 to 2006) using the search strategy detailed in Appendix 1.

\section{Searching other resources}

We searched the citation lists of relevant publications, review articles and included studies. After the identification of studies, the primary author contacted some experts in the field via electronic mail. The list of potential included trials was sent to them. They were asked if they were aware of additional trials, published, unpublished or ongoing, that have been conducted in this area (postpartum weight loss).

We did not apply any language restrictions.

\section{Data collection and analysis}




\section{Trial selection}

Three independent authors (AR Amorim, PMC Lourenco and YM Linne) considered studies for inclusion. The selection process was divided into two stages. Initially, we scanned titles, abstracts and keywords of every article retrieved to determine whether each article met the predetermined eligibility criteria, such as: included postpartum women involved at least one of the selected interventions and assessed one or more relevant clinical outcomes. In the presence of doubt about article inclusion, the decision was taken at the next stage. In the second stage, we obtained the full text of the article to clarify doubts about eligibility criteria. The discrepancies in selecting studies were resolved by discussion. Details of excluded studies are available in the Characteristics of excluded studies table.

\section{Data extraction}

The three authors independently extracted information from the included studies and entered data into the Review Manager software (RevMan 2003). Data extraction forms, developed by the primary author were tested in a pilot study. When needed, we requested further information or data from trial authors. We resolved differences in data extraction by consensus, referring back to the original article.

\section{Multiple publications}

In order to identify instances of multiple publication, we extracted information about characteristics of the participants, type of intervention, time period and place of study from all papers. Additionally, the primary author contacted the trial authors to confirm if the articles reported results of the same study. They were asked if participants, type of intervention and time period of study were exactly the same. In the case of multiple publications, we considered the most complete articles, such as those including greater numbers of outcomes and more methodological information, as primary references.

\section{Quality assessment}

We assessed methodological quality of each included study according to the criteria described in the Cochrane Reviewers' Handbook (Alderson 2004). Methods used for generation of the randomisation sequence were described for each trial.

Quality scores for concealment of allocation:

(A) adequate: assignment to groups was determined by central off-site randomisation, sequentially-numbered, sealed, opaque envelopes or other appropriate schemes and so could not be influenced by the investigators;

(B) unclear;

(C) inadequate: alternation, the use of case record numbers, dates of birth or day of the week, tossing a coin, and any procedure that is entirely transparent before allocation;
(D) not used.

For completeness of follow up:

(A) adequate: less than $20 \%$ of withdrawal or loss to follow up;

(B) unclear;

(C) inadequate: more than $20 \%$ of withdrawal or loss to follow up.

For blinding of outcome assessment:

(A) adequate: the investigator who assessed the results did not know the allocated treatment;

(B) unclear;

(C) no blinding: the investigator knew the allocated treatment.

Double blinding was impossible in these kinds of trials, as the participants knew which intervention they received. Blinding of those assessing the results (single blinding) was, however, highlighted and we planned to consider it in a separate sensitivity analysis.

Based on these quality criteria, we subdivided studies into the following three broad categories:

(A) low risk of bias: all quality criteria met;

(B) moderate risk of bias: one or more of the quality criteria only partly met;

(C) high risk of bias: one or more criteria not met.

The authors evaluated methodological quality of trials independently. We did not assess trials blindly, as we knew the names of trial authors and institutions, as well as the source of publication. Differences highlighted here were resolved through consultation with the other authors, and a judgment was made based on consensus. We did not exclude studies on the basis of a low-quality score. Thus, this classification was used as the basis of a sensitivity analysis.

\section{Data analysis}

When data were available, sufficiently similar and of sufficient quality, we performed statistical analyses using the Review Manager software (RevMan 2003). For continuous outcomes, results were expressed as mean difference between the postintervention values, or the difference between baseline values and postintervention values. When all trials assessed the same outcome, but measured it in a variety of ways or in different scales, the standardised mean difference was used as a summary statistic. For dichotomous outcomes, results for each study were expressed as risk ratios. Both dichotomous and continuous outcomes were presented with $95 \%$ confidence intervals. When information was provided in the article, an intention-to-treat analysis was planned to be performed.

\section{Assessment of heterogeneity}

Firstly, we analysed all data with a fixed-effect model. The $\mathrm{I}^{2}$ statistic was applied to describe the proportion of total variation in study estimates that was due to heterogeneity. An $\mathrm{I}^{2}$ of more than $50 \%$ was considered as notable heterogeneity. When we found high levels of heterogeneity, we performed subgroup and sensitivity analyses, excluding the trials most susceptible to bias. Whether 
pooling of results seemed appropriate, heterogeneity that was not explained by subgroup and sensitivity analyses was modelled using a random-effects analysis, which assumes that the effect size varies across studies.

\section{Subgroup analyses}

These analyses aimed to assess whether particular groups of participants could obtain more benefit from an intervention than other groups could or evaluate if the treatment effect varied with different intervention characteristics.

Our prespecified subgroups were based on:

- dietary advice versus prescription of caloric restriction;

- exercise counselling (self-supervised exercise) versus structured exercise programme (supervised exercise sessions);

- duration of intervention: short-term and medium-term versus long-term.

We did not conduct all subgroup analyses, due to insufficient data. We carried out only the analyses for postpartum weight loss in the comparison group of diet plus exercise versus usual care. We will include these analyses in future updates, once sufficient data are available. Only the primary outcomes listed above will be included in the subgroup analyses.

\section{Sensitivity analyses}

Sensitivity analyses aimed to assess robustness of results to allocation concealment, blinding of outcome assessors, losses to follow up and other study characteristics. We planned to perform these analyses in order to explore the influence of the following factors on effect size:

- repeating the analysis, excluding unpublished studies;

- repeating the analysis, taking account of study quality, as previously specified in quality assessment section. The results of high-quality studies will be compared with those of poorer quality studies, where studies rated A for all quality criteria will be compared with those rated $\mathrm{B}$ or C;

- repeating the analysis, excluding quasi-randomised trials;

- repeating the analysis, excluding any very large or long-term trials to establish how much they dominate the result.

Our prespecified sensitivity analyses have not been completely conducted, due to the small number of studies included in the meta-analysis. We repeated only the analysis excluding any very large or long-term trials in the comparison group of diet plus exercise versus usual care. We will include the entire analysis in future updates, when sufficient data become available.

We also planned to use funnel plots and a simple graphical test to assess for evidence of bias (Egger 1997). However, the number of eligible studies was too few to allow adequate assessment.

\section{R E S U L T S}

\section{Description of studies}

See: Characteristics of included studies; Characteristics of excluded studies; Characteristics of ongoing studies.

We found 11 reports of studies which qualified for inclusion in this review. Some papers reported results of the same study. We considered reports by Dewey 1994b, Prentice 1994 and Lovelady 1995, which described the effects of aerobic exercise among women during lactation, as a single study. Likewise, we considered articles by Lovelady 2000, Lovelady 2001, Lovelady 2006 and Mukherjea 2000, which described the effect of energy restriction and exercise among breastfeeding women, as a single study. After this procedure, the review included data of six studies. One article contributed information for three comparison groups: diet versus usual care; diet plus exercise versus usual care; diet plus exercise versus diet alone (McCrory 1999). [Twenty-three reports from an updated search in December 2011 have been added to Studies awaiting classification.]

We were able to get outcome data for all trials except one. O'Toole et al stated that fat-free mass was measured, but data were not available in the article (O'Toole 2003).

The trials were primarily conducted in the United States (Dewey 1994a; Leermakers 1998; Lovelady 2000; McCrory 1999; O’Toole 2003), but one was conducted in Australia (Armstrong 2003). Most trials were classified as short- and medium-term study, and only one trial provided long-term outcome data. The longterm trial comprised a one-year intervention programme (O'Toole 2003). Although the majority of trials involved a prescription of a calorie-restricted diet, the trial by Leermakers 1998 involved nutritional education. All trials involved aerobic exercise programmes; three were based on supervised exercise sessions (Armstrong 2003; Dewey 1994a; Lovelady 2000), and the rest focused on self-monitored sessions (Leermakers 1998; McCrory 1999; O’Toole 2003). Armstrong 2003 recruited women between six weeks and 12 months postpartum. No information about BMI and breastfeeding status was available. Dewey 1994a recruited exclusively breastfeeding women between six and eight weeks postpartum. No information about BMI at baseline was available. Leermakers 1998 recruited non-breastfeeding women, between three and 12 months postpartum, who exceeded their prepregnancy weight by at least $6.8 \mathrm{~kg}$. The mean $( \pm$ SD) BMI at baseline was $29.1 \pm 3.7$ and $30.6 \pm 5.0$ in the diet plus exercise and usual care group, respectively. Lovelady 2000 recruited, at 4 weeks postpartum, exclusively breastfeeding women who were overweight. The mean BMI at baseline was $27.6 \pm 2.4$ and $28.0 \pm 2.1$ in the diet plus exercise and usual care group, respectively. McCrory 1999 recruited exclusively breastfeeding women between eight and six weeks postpartum. The mean BMI at baseline was $25.3 \pm 4.8,25.4 \pm 4.1$ and 24.9 \pm 3.8 in the diet, diet plus exercise and usual care group, respectively. O’Toole 2003 recruited non-breastfeeding women between 
six weeks and six months postpartum. The mean BMI at baseline was $29.8 \pm 2.0$ and $29.9 \pm 2.9$ in diet plus exercise and usual care group, respectively.

Of the 19 excluded reports, four articles were related to the same study (Fahrenwald 2002; Fahrenwald 2003; Fahrenwald 2004; Fahrenwald 2005). These articles were considered as a single study, leaving the number of 16 excluded studies. We found only one ongoing trial. Details for each can be found in the following tables: Characteristics of included studies; Characteristics of excluded studies and Characteristics of ongoing studies.

\section{Risk of bias in included studies}

In four of six studies, the method of randomisation was adequate (Armstrong 2003; Dewey 1994a; Lovelady 2000; McCrory 1999). In the remaining two studies, it is stated that intervention was randomly assigned, but the method was not reported (Leermakers 1998; O'Toole 2003). Allocation concealment was adequate in all trials, except one (Leermakers 1998) in which the allocation process was unreported. Follow-up attrition rates were less than 20\% in all trials but two (Leermakers 1998; O’Toole 2003). Outcome data were not collected by investigators blinded to group allocation in any trial.

\section{Effects of interventions}

We included six trials involving 245 women. All included studies were identified by the Cochrane Pregnancy and Childbirth Group's Trials Register and none of them were indexed within the LILACS database.

Initially, the results about heterogeneity assessment are presented, and then findings are shown in sequential order, starting with comparison one and the primary outcomes, followed by the secondary outcomes.

\section{Heterogeneity}

We used a fixed-effect model to analyse these data. We found significant heterogeneity in two outcomes included in comparison three (diet plus exercise versus usual care). The results of postpartum weight loss using a fixed-effect model showed an $\mathrm{I}^{2}$ value of $83.1 \%\left(\mathrm{Chi}^{2}=17.78 ; \mathrm{df}=3 ; \mathrm{P}=0.0005\right)$. When analysed using a random-effects model the mean difference (MD) changed from $-1.59 \mathrm{~kg}(95 \%$ confidence interval (CI) -1.90 to -1.28$)$ to -2.89 (95\% CI -4.83 to -0.95$)$. Similarly, the results of change in percentage of body fat using a fixed-effect model showed an $\mathrm{I}^{2}$ value of $74.6 \%\left(\mathrm{Chi}^{2}=7.87 ; \mathrm{df}=2 ; \mathrm{P}=0.02\right)$. The random-effects model showed that MD changed from $-1.93 \mathrm{~kg}$ (95\% CI -2.63 to $-1.22)$ to -2.21 (95\% CI -4.03 to -0.40$)$.

There was no overlap between the CIs of effect estimation in the Lovelady and McCrory trials (Lovelady 2000; McCrory 1999), which might have resulted in statistical heterogeneity. The heterogeneity disappeared in both outcomes after repeating the analysis excluding McCrory's trials (see subgroup analyses). When excluding Lovelady's trial from the analysis, the heterogeneity reduced from $83.1 \%$ to $31.4 \%$ in the primary outcome (postpartum weight loss) and disappeared in the secondary outcome (results not shown). We believe that this meta-analysis may have been affected by low magnitude of weight loss and body fat reduction reported in McCrory's trial compared to others (McCrory 1999). The low magnitude of these outcomes might be explained by the short duration of the intervention (11 days). However, the assessment of heterogeneity was limited to aid the decision regarding pooling the results due to the small number of studies included. It seemed more appropriate to summarise the results using a random-effects model, instead of excluding a potentially influential study from the meta-analysis.

\section{(I) Diet versus usual care}

\section{Primary outcomes}

Only one trial, involving only exclusively breastfeeding women, contributed data for this comparison group. Women who followed a calorie-restricted diet lost significantly more weight than women who received usual care $(\mathrm{n}=45$; MD $-1.70 \mathrm{~kg} ; 95 \%$ CI -2.08 to -1.32). The other primary outcome measures were not assessed.

\section{Secondary outcomes}

Data were available for the following prespecified outcomes: change in percentage of body fat, fat-free mass, basal plasma prolactin concentration and milk volume. Women allocated in the diet group lost significantly more fat-free mass than women in the usual care (MD $-0.90 \mathrm{~kg}$; $95 \% \mathrm{CI}-1.38$ to -0.42 ). There were not significant differences between the diet and control groups in relation to body fat (MD $-0.40 \%$ body fat; $95 \%$ CI -1.15 to 0.35 ), plasma prolactin concentration (MD $2.24 \mu \mathrm{g} / \mathrm{mL}$; $95 \% \mathrm{CI}$ -13.95 to 18.43 ) and milk volume (MD $18.00 \mathrm{~g} /$ day; $95 \% \mathrm{CI}$ 63.87 to 27.87$)$.

\section{(2) Exercise versus usual care}

\section{Primary outcomes}

Data were available for only one primary outcome, which showed that exercise was not significantly associated with postpartum weight loss among exclusively breastfeedng women (one trial; $\mathrm{n}=$ 33; MD $0.00 \mathrm{~kg}$; $95 \% \mathrm{CI}-8.63$ to 8.63 ). 


\section{Secondary outcomes}

No significant differences were found between the exercise and usual care groups regarding change in percentage of body fat (one trial; $\mathrm{n}=33$; MD $0.20 \%$ body fat; $95 \% \mathrm{CI}-5.40$ to 5.80 ), fatfree mass (one trial; $\mathrm{n}=33$; MD $0.30 \mathrm{~kg}$; $95 \% \mathrm{CI}-3.78$ to 4.38 ), plasma prolactin concentration (one trial; $\mathrm{n}=33$; $\mathrm{MD}-6.73 \mu \mathrm{g}$ / $\mathrm{mL} ; 95 \% \mathrm{CI}-54.62$ to 41.16 ), milk volume (one trial; $\mathrm{n}=33$; MD $40.00 \mathrm{~g} /$ day; $95 \% \mathrm{CI}-109.16$ to 189.16 ) and infant weight gain (one trial; $\mathrm{n}=33$; MD $26.17 \mathrm{~g}$; 95\% CI -756.15 to 808.49 ). Two studies reported significant improvement in cardiorespiratory fitness in the exercise group $(\mathrm{n}=53$; MD $7.08 \mathrm{~mL} / \mathrm{kg} /$ minute; $95 \%$ CI 4.03 to 10.13$)$.

\section{(3) Diet plus exercise versus usual care}

\section{Primary outcomes}

Diet combined with exercise was significantly associated with postpartum weight loss (four trials; $\mathrm{n}=169$; MD $-2.89 \mathrm{~kg}$; 95\% CI 4.83 to -0.95 ). Women who followed a dietary and exercise programme were significantly more likely to return to prepregnancy weight (two trials; $\mathrm{n}=102$; risk ratio (RR) 2.55; 95\% CI 1.20 to 5.41) and achieve healthy weight (two trials; $\mathrm{n}=63$; $\mathrm{RR} 4.68$; $95 \%$ CI 1.32 to 16.32 ) than women who received usual care.

\section{Secondary outcomes}

Diet combined with exercise significantly reduced the percentage of body fat (three trials; $\mathrm{n}=107$; MD $-2.21 \%$ body fat; $95 \%$ CI -4.03 to -0.40 ) and improved cardiorespiratory fitness (two trials; $\mathrm{n}=63$; MD $3.76 \mathrm{~mL} / \mathrm{kg} /$ minute; $95 \%$ CI 1.46 to 6.07 ) among postpartum women compared to usual care. No significant differences were found between the diet plus exercise and usual care groups regarding change in fat-free mass (two trials; $\mathrm{n}=84 ; \mathrm{MD}$ $-0.20 \mathrm{~kg} ; 95 \% \mathrm{CI}-0.67$ to 0.27 ), plasma prolactin concentration (one trial; $\mathrm{n}=43$; MD $3.40 \mu \mathrm{g} / \mathrm{mL}$; 95\% CI -6.77 to 13.57 ), milk volume (one trial; $\mathrm{n}=45$; $\mathrm{MD}-33.00 \mathrm{~g} /$ day; $95 \% \mathrm{CI}-81.25$ to 15.25), infant length gain (one trial; $\mathrm{n}=30$; $\mathrm{MD} 0.50 \mathrm{~cm} ; 95 \%$ $\mathrm{CI}-0.65$ to 1.65 ) and infant weight gain (one trial; $\mathrm{n}=30$; $\mathrm{MD}$ $64.00 \mathrm{~g} ; 95 \% \mathrm{CI}-271.87$ to 399.87$)$.

\section{(4) Diet versus exercise}

No study reporting this comparison group was identified.

\section{(5) Diet plus exercise versus exercise alone}

No study reporting this comparison group was identified.

\section{(6) Diet plus exercise versus diet alone}

\section{Primary outcomes}

Only one trial, involving only exclusively breastfeeding women, contributed data for this comparison group. There was no significant difference in weight loss between the diet and diet plus exercise groups ( $\mathrm{n}=43$; MD $0.30 \mathrm{~kg}$; $95 \%$ CI -0.06 to 0.66 ). The other primary outcome measures were not assessed.

\section{Secondary outcomes}

Women allocated in the diet plus exercise group lost more body fat than women in the diet group (MD - $0.70 \%$ body fat; $95 \%$ CI -1.44 to 0.04 ). On the other hand, the diet group lost significantly more fat-free mass than the diet plus exercise group (MD 0.70 $\mathrm{kg}$; $95 \%$ CI 0.24 to 1.16). Nonsignificant results were observed regarding plasma prolactin concentration (MD $1.16 \mu \mathrm{g} / \mathrm{mL} ; 95 \%$ $\mathrm{CI}-13.86$ to 16.18 ) and milk volume (MD -15.00 g/day; $95 \%$ 62.34 to 32.34$)$.

\section{DISCUSSION}

\section{Postpartum weight loss}

The results suggest diet or diet plus exercise are effective strategies in reducing body weight. Exercise seems to have no effect on weight loss, body fatness and fat-free mass, but significantly improved maternal cardiovascular fitness. These results about weight loss require confirmation because they are based primarily on one single study, including only 33 subjects. However, the effect of exercise programmes on cardiovascular fitness seems consistent across two trials (Armstrong 2003; Dewey 1994b). One possible reason for no difference on body weight between the exercise and usual care groups is that women who exercised could have increased their energy consumption. Thus, they did not reach the energy deficit required to impose weight loss. However, Dewey et al reported that the difference in energy intakes at baseline remained unaltered during the study period. The authors suggested that the mothers who exercised compensated their increased energy expenditure by reducing other daily activity (Dewey 1994b).

In contrast to our finding, meta-analysis evaluating the effect of exercise, with or without dieting, on the body composition of overweight subjects found that aerobic exercise without dietary restriction among women caused a modest but significant weight loss (1.4 kg in 12 weeks), compared with sedentary controls. Similar to our results, the study showed little effect of aerobic exercise on fat-free mass. The meta-analysis demonstrated that resistance exercise had little effect on weight loss, but increased significantly 
fat-free mass (Garrow 1995). We could not test this hypothesis because all trials involved only aerobic exercises.

Both diet and diet combined with exercise were significantly associated with postpartum weight loss when compared to the usual care group. Women assigned to the combined intervention were significantly more likely to return to prepregnancy weight and achieve healthy weight, which may help to prevent women from becoming overweight or obese after childbearing. There was no difference in the magnitude of weight loss and change in percentage of body fat between the diet and diet plus exercise groups. However, the decrease in fat-free mass was significantly higher in the diet group than in the diet plus exercise group. According to the preliminary results, it seems advisable to lose weight by a combination of dieting and exercise, rather than by dieting alone, because the former improves the cardiovascular fitness level of the mothers and preserves fat-free mass. Diet alone, on the other hand, reduces maternal fat-free mass. This finding corroborates other meta-analyses, which found that exercise provides some conservation of fat-free mass during weight loss by dieting (Ballor 1994; Garrow 1995). Although this review showed that change in body weight was statistically significant in the diet plus exercise group, the magnitude of postpartum weight loss was moderate (approximately $3 \mathrm{~kg}$ ). Due to lack of information about maternal health outcomes related to excess body weight and the small number of studies included in the meta-analysis, the clinical importance of the intervention programme remains unclear, particularly for women who were already overweight or obese before pregnancy. Since the data were gathered only in affluent countries, it is unknown if these findings can be applied to other populations.

It is important to note that there was considerable clinical heterogeneity between trials (in comparison 03 ), probably because of differences in the type or length/period of the intervention and differences in the participants' characteristics. Statistical heterogeneity was also identified. Due to the small number of trials, all explanations for the observed heterogeneity remain highly speculative. Therefore, overall effects were calculated using a randomeffects model.

\section{Effect of interventions on breastfeeding performance}

Results on breastfeeding performance were limited to trials that included exclusively breastfeeding women (three studies). The findings indicated that none of the interventions adversely affected milk volume and plasma prolactin concentration. Due to lack of data, we could only evaluate impact on infant length and weight gain among women who followed a diet plus exercise intervention. The results showed no significant difference in both outcomes. Milk Ig A concentration, number of women who stopped breastfeeding and breastfeeding duration were not assessed in any trial. Within these limits and those imposed by small sample sizes, the results seem reasonably consistent, showing that the interventions appear safe for breastfeeding women.

\section{A U T HOR S' CONCLUSIONS}

\section{Implications for practice}

Preliminary findings suggest that exercise alone improves cardiovascular fitness, but does not increase the rate of postpartum weight loss. Furthermore, diet combined with exercise or diet alone compared to usual care enhance weight loss during postpartum and play a role in preventing future maternal obesity. However, it may be preferable to lose weight through a combination of dieting and exercise to dieting alone, because the former improves maternal cardiovascular fitness level and preserves lean body mass. Diet or exercise, or both, appears safe for breastfeeding women. Unfortunately, the available data are insufficient to infer important risks or other potential benefits for the mother or infant. Methodological shortcomings of some trials, especially the small sample size, the small number of studies reviewed for each outcome, and the diversity in the nature, duration and frequency of the interventions argue caution in applying these encouraging results.

\section{Implications for research}

Future trials will require much larger sample sizes to detect potential effects on milk volume, plasma prolactin concentration and infant length and weight gain. In addition, the studies should assess the potential impacts on milk Ig A concentration, number of women who stopped breastfeeding and breastfeeding duration. Other outcomes, such as maternal morbidity and adverse events should also be studied. In addition, it would be interesting to examine the impact of weight-loss programmes on maternal selfimage and self-esteem.

The suggestion that regular aerobic exercise may not affect weight loss and body composition also merits further study. Likewise, future trials should attempt to confirm the limited evidence suggesting that diet alone or diet plus exercise enhance postpartum weight loss. It is still not clear if diet plus exercise is an effective strategy in low-income women, which suggests this as an area for future study. Future trials should ensure strict and concealed randomisation, intention-to-treat analysis, and adequate blinding of examiners. Finally, since adherence to weight-loss programmes requires considerable effort, more information is necessary on women's satisfaction and compliance with such interventions. These outcomes should be evaluated in a systematic fashion.

[Note: The 23 citations in the awaiting classification section of the review may alter the conclusions of the review once assessed.] 


\section{ACKNOWLEDG EMENTS}

As part of the pre-publication editorial process, this review has been commented on by three peers (an editor and two referees who are external to the editorial team), one or more members of the Pregnancy and Childbirth Group's international panel of consumers and the Group's Statistical Adviser.

We thank A Adegboye for the constructive criticism and help with grammar and spelling.

\section{RE FER E N C E S}

\section{References to studies included in this review}

Armstrong 2003 \{published data only\}

Armstrong K, Edwards $\mathrm{H}$. The effects of exercise and social support on mothers reporting depressive symptoms: a pilot randomized controlled trial. International Journal of Mental Health Nursing 2003;12:130-8.

Dewey 1994a \{published and unpublished data\} * Dewey KG, Lovelady CA, Nommsen-Rivers LA, McCrory MA, Lonnerdal B. A randomized study of the effects of aerobic exercise by lactating women on breast-milk volume and composition. New England Journal of Medicine 1994; 330(7):449-53.

Lovelady CA, Nommsen-Rivers LA, McCrory MA, Dewey KG. Effects of exercise on plasma lipids and metabolism of lactating women. Medicine \& Science in Sports \& Exercise 1995;27(1):22-8.

Prentice A. Should lactating women exercise?. Nutrition

Reviews 1994;52(10):358-60.

Leermakers 1998 \{published data only\}

Leermakers EA, Anglin K, Wing RR. Reducing postpartum weight retention through a correspondence intervention. International Journal of Obesity and Related Metabolic Disorders 1998;22(11):1103-9.

Lovelady 2000 \{published and unpublished data\}

* Lovelady CA, Garner KE, Moreno KL, Williams JP. The effect of weight loss in overweight, lactating women on the growth of their infants. New England Journal of Medicine 2000;342(7):449-53.

Lovelady CA, Stephenson KG, Kuppler KM, Williams JP. The effects of dieting on food and nutrient intake of lactating women. Journal of the American Dietetic Association 2006;106(6):908-12.

Lovelady CA, Williams JP, Garner KE, Moreno KL, Taylor $\mathrm{Ml}$, Leklem JE. Effect of energy restriction and exercise on vitamin B-6 status of women during lactation. Medicine \& Science in Sports \& Exercise 2001;33(4):512-8.

Mukherjea R, Moser-Veillon P, Lovelady C. Effect of exercise and energy restriction on leptin during lactation. Advances in Experimental Medicine and Biology 2000;478: $417-8$.
McCrory 1999 \{published and unpublished data\} McCrory MA, Nommsen-Rivers LA, Mole PA, Lonnerdal B, Dewey KG. Randomized trial of the short-term effects of dieting compared with dieting plus aerobic exercise on lactation performance. American Journal of Clinical Nutrition 1999;69(5):959-67.

O’Toole 2003 \{published data only\} O’Toole ML, Sawicki MA, Artal R. Structured diet and physical activity prevent postpartum weight retention. Journal of Women's Health 2003;12(10):991-8.

\section{References to studies excluded from this review}

Armstrong 2004 \{published data only\}

Armstrong K, Edwards H. The effectiveness of a pramwalking exercise programme in reducing depressive symptomatology for postnatal women. International Journal of Nursing Practice 2004;10(4):177-94.

Bopp 2005 \{published data only\} Bopp M, Lovelady C, Hunter C, Kinsella T. Maternal diet and exercise: effects on long-chain polyunsaturated fatty acid concentrations in breast milk. Journal of the American Dietetic Association 2005;105(7):1098-103.

Carey 1997 \{published data only\} Carey GB, Quinn TJ, Goodwin SE. Breast milk composition after exercise of different intensities. Journal of Human Lactation 1997;13(2):115-20.

Duckman 1968 \{published data only\} Duckman S, Chen W, Weir JH. Double-blind evaluation of chlorphentermine hydrochloride vs placebo in postpartum weight control. Current Therapeutic Research 1968;10: 619-25.

Fahrenwald 2004 \{published data only\} Fahrenwald NL, Atwood JR, Johnson DR. Mediator analysis of Moms on the move. Western Journal of Nursing Research 2005;27(3):271-91.

* Fahrenwald NL, Atwood JR, Walker SN, Johnson DR, Berg K. A randomized pilot test of "Moms on the Move": a physical activity intervention for WIC mothers. Annals of Behavioral Medicine 2004;27(2):82-90.

Fahrenwald NL, Sharma M. Development and expert evaluation of "Moms on the Move," a physical activity 
intervention for WIC mothers. Public Health Nursing 2002; 19(6):423-39.

Fahrenwald NL, Walker SN. Application of the Transtheoretical Model of behavior change to the physical activity behavior of WIC mothers. Public Health Nursing 2003;20(4):307-17.

Fly 1998 \{published data only\}

Fly AD, Uhlin KL, Wallace JP. Major mineral concentrations in human milk do not change after maximal exercise testing. American Journal of Clinical Nutrition 1998;68(2):345-9.

Gregory 1997 \{published data only\}

Gregory RL, Wallace JP, Gfell LE, Marks J, King BA. Effect of exercise on milk immunoglobulin A. Medicine \& Science in Sports \& Exercise 1997;29(12):1596-601.

Koltyn 1997 \{published data only\}

Koltyn KF, Schultes SS. Psychological effects of an aerobic exercise session and a rest session following pregnancy. Journal of Sports Medicine and Physical Fitness 1997;37(4): 287-91.

Krummel 2004 \{published data only\} Krummel DA, Semmens E, Boury J, Gordon PM, Larkin KT. Stages of change for weight management in postpartum women. Journal of the American Dietetic Association 2004; 104(7):1102-8.

Lovelady 2003 \{published data only\} Lovelady CA, Hunter CP, Geigerman CM. Effect of exercise on immunologic factors in breast milk. Pediatrics 2003;111 (2):148-52.

Ostbye 2003 \{published data only\}

Ostbye T, McBride C, Demark-Wahnefried W, Bastian L, Morey M, Krause KM, et al.Interest in healthy diet and physical activity interventions peripartum among female partners of active duty military. Military Medicine 2003; 168(4):320-5.

Quinn 1999 \{published data only\}

Quinn TJ, Carey GB. Does exercise intensity or diet influence lactic acid accumulation in breast milk?. Medicine \& Science in Sports \& Exercise 1999;31(1):105-10.

Wallace 1991 \{published data only\} Wallace JP, Rabin J. The concentration of lactic acid in breast milk following maximal exercise. International Journal of Sports Medicine 1991;12(3):328-31.

Wallace 1992a \{published data only\}

Wallace JP, Ernsthausen K, Inbar G. The influence of the fullness of milk in the breasts on the concentration of lactic acid in postexercise breast milk. International Journal of Sports Medicine 1992;13(5):395-8.

Wallace 1992b \{published data only\}

Wallace JP, Inbar G, Ernsthausen K. Infant acceptance of postexercise breast milk. Pediatrics 1992;89:1245-7.

Wright 2002 \{published data only\}

Wright KS, Quinn TJ, Carey GB. Infant acceptance of breast milk after maternal exercise. Pediatrics 2002;109: 585-9.

\section{References to studies awaiting assessment}

Aittasalo 2008 \{published data only\}

Aittasalo M, Pasanen M, Fogelholm M, Kinnunen TI, Ojala K, Luoto R. Physical activity counseling in maternity and child health care - a controlled trial. BMC Women's Health 2008;8: 14 .

Bastian 2010 \{published data only\}

Bastian LA, Pathiraja VC, Krause K, Namenek Brouwer RJ, Swamy GK, Lovelady CA, et al.Multiparity is associated with high motivation to change diet among overweight and obese postpartum women. Womens Health Issues 2010;20 (2):133-8.

Brouwer 2006 \{published data only\} Brouwer RN, Krause K. Promoting postpartum weight loss in overweight women (ongoing trial). ClinicalTrials.gov (http://clinicaltrials.gov/) (accessed 21 March 2006) 2006.

Craigie 2011 \{published data only\}

Craigie AM, Macleod M, Barton KL, Treweek S, Anderson AS. Supporting postpartum weight loss in women living in deprived communities: Design implications for a randomised control trial. European Journal of Clinical Nutrition 2011;65(8):952-8.

Cramp 2006 \{published data only\}

Cramp AG, Brawley LR. Moms in motion: a groupmediated cognitive-behavioral physical activity intervention. International Journal of Behavioral Nutrition and Physical Activity 2006;3:23.

Davenport 2011 \{published data only\} Davenport MH, Giroux I, Sopper MM, Mottola MF. Postpartum exercise regardless of intensity improves chronic disease risk factors. Medicine and Science in Sports and Exercise 2011;43(6):951-8.

Ebbeling 2007 \{published data only\} Ebbeling CB, Pearson MN, Sorensen G, Levine RA, Hebert JR, Salkeld JA, et al.Conceptualization and development of a theory-based healthful eating and physical activity intervention for postpartum women who are low income. Health Promotion Practice 2007;8(1):50-9.

Ferrara 2008 \{published data only\}

Ferrara A. Diet, exercise and breastfeeding intervention program for women with gestational diabetes (DEBI Trial). ClinicalTrials.gov (http://clinicaltrials.gov/) (accessed 20 February 2008) 2008.

Ferrara 2011 \{published data only\}

Ferrara A, Hedderson MM, Albright CL, Ehrlich SF, Quesenberry CP=J, Peng T, et al.A pregnancy and postpartum lifestyle intervention in women with gestational diabetes mellitus reduces diabetes risk factors: a feasibility randomized control trial. Diabetes Care 2011;34(7): 1519-25.

Fjeldsoe 2010 \{published data only\} Fjeldsoe BS, Miller YD, Marshall AL. MobileMums: a randomized controlled trial of an SMS-based physical activity intervention. Annals of Behavioral Medicine 2010; 39(2):101-11. 
Huang 2011 \{published data only\}

Huang TT, Yeh CY, Tsai YC. A diet and physical activity intervention for preventing weight retention among Taiwanese childbearing women: a randomised controlled trial. Midwifery 2011;27(2):257-64.

Kearney 2005 \{published data only\}

Kearney M. Influences on postpartum weight retention: pilot study. Virginia Henderson International Nursing Library (www.nursinglibrary.org) (accessed 10 January 2007) 2005

Kearney 2006 \{published data only\}

Kearney MH, Simonelli MC. Intervention fidelity: lessons learned from an unsuccessful pilot study. Applied Nursing Research 2006;19(3):163-6.

Keller 2011 \{published data only\}

Keller C, Records K, Ainsworth B, Belyea M, Permana P, Coonrod D, et al.Madres para la Salud: design of a theorybased intervention for postpartum Latinas. Contemporary Clinical Trials 2011;32(3):418-27.

Krummel 2010 \{published data only\}

Krummel D, Semmens E, MacBride AM, Fisher B. Lessons learned from the Mothers' Overweight Management Study in 4 West Virginia WIC Offices. Journal of Nutrition Education and Behavior 2010;42(3 Suppl):S52-8.

Liu 2009 \{published data only\}

Liu N, Mao L, Sun X, Liu L, Yao P, Chen B. The effect of health and nutrition education intervention on women's postpartum beliefs and practices: a randomized controlled trial. BMC Public Health 2009;9:45.

Lovelady 2009 \{published data only\} Lovelady CA, Bopp MJ, Colleran HL, Mackie HK, Wideman L. Effect of exercise training on loss of bone mineral density during lactation. Medicine \& Science in Sports \& Exercise 2009;41(10):1902-7.

Mohammad 2011 \{published data only\}

Mohammad MA, Sunehag AL, Rodriguez LA, Haymond MW. Galactose promotes fat mobilization in obese lactating and nonlactating women. American Journal of Clinical Nutrition 2011;93(2):374-81.

Moreau 2007 \{published data only\}

Moreau M, Chadoutaud B, Msika P. An innovative nutraceutical compound for postpartum localized overweight or for postpartum body remodeling. Journal of the American Academy of Dermatology 2007;56(2):AB89, Abstract no: P1019.

Norman 2010 \{published data only\}

Norman E, Sherburn M, Osborne RH, Galea MP. An exercise and education program improves well-being of new mothers: a randomized controlled trial. Physical Therapy 2010;90(3):348-55.

Ostbye 2008 \{published data only\}

Ostbye T, Krause KM, Brouwer RJ, Lovelady CA, Morey MC, Bastian LA, et al.Active Mothers Postpartum (AMP): rationale, design, and baseline characteristics. Journal of Women's Health 2008;17(10):1567-75.
Ostbye 2009 \{published data only\}

Ostbye T, Krause KM, Lovelady CA, Morey MC, Bastian LA, Peterson BL, et al.Active Mothers Postpartum: a randomized controlled weight-loss intervention trial. American Journal of Preventive Medicine 2009;37(3): 173-80.

Stendell-Hollis 2011 \{published data only\} Stendell-Hollis NR, Laudermilk MJ, West JL, Thompson PA, Thomson CA. Recruitment of lactating women into a randomized dietary intervention: Successful strategies and factors promoting enrollment and retention. Contemporary Clinical Trials 2011;32(4):505-11.

\section{References to ongoing studies}

Peterson 2002 \{published data only\}

Peterson KE, Sorensen G, Pearson M, Hebert JR, Gottlieb BR, McCormick MC. Design of an intervention addressing multiple levels of influence on dietary and activity patterns of low-income, postpartum women. Health Education Research 2002;17(5):531-40.

\section{Additional references}

\section{AbuSabha 1998}

AbuSabha R, Greene G. Body weight, body composition, and energy intake changes in breastfeeding mothers. Journal of Human Lactation 1998;14(2):119-24.

\section{Alderson 2004}

Alderson P, Green S, Higgins JPT, editors. Cochrane Reviews' Handbook 4.2.2 [updated March 2004]. http: //www.cochrane.org/resources/handbook/hbook.htm (accessed 26 September 2004).

Ballor 1994

Ballor DL, Poehlman ET. Exercise-training enhances fatfree mass preservation during diet-induced weight loss: a meta-analytical finding. International Journal of Obesity and Related Metabolic Disorders 1994;18(1):35-40.

\section{Clark 1999}

Clark M, Ogden J. The impact of pregnancy on eating behaviour and aspects of weight concern. International Journal of Obesity and Related Metabolic Disorders 1999;23 (1):18-24.

\section{Coward 1984}

Coward WA, Paul AA, Prentice AM. The impact of malnutrition on human lactation: observations from community studies. Federation Proceedings 1984;43(9): 2432-7.

Crowell 1995

Crowell DT. Weight change in postpartum period. A review of the literature. Journal of Nurse-Midwifery 1995;40(5): 418-23.

DeCs 2004

Health Sciences Descriptors (DeCS). Virtual Health Library (VHL). http://decs.bvs.br/ (accessed 11 August 2004).

Dewey 1994b

Dewey KG, Lovelady CA, Nommsen-Rivers LA, McCrory MA, Lonnerdal B. A randomized study of the effects of 
aerobic exercise by lactating women on breast-milk volume and composition. New England Journal of Medicine 1994; 330(7):449-53.

\section{Dusdieker 1994}

Dusdieker LB, Hemingway DL, Stumbo PJ. Is milk production impaired by dieting during lactation?. American Journal of Clinical Nutrition 1994;59(4):833-40.

\section{Egger 1997}

Egger M, Davey Smith G, Schneider M, Minder C. Bias in meta-analysis detected by a simple, graphical test. $B M J$ 1997;315(7109):629-34. [MEDLINE: 9310563]

\section{Fahrenwald 2002}

Fahrenwald NL, Sharma M. Development and expert evaluation of "Moms on the Move," a physical activity intervention for WIC mothers. Public Health Nursing 2002; 19(6):423-39.

\section{Fahrenwald 2003}

Fahrenwald NL, Walker SN. Application of the Transtheoretical Model of behavior change to the physical activity behavior of WIC mothers. Public Health Nursing 2003;20(4):307-17.

\section{Fahrenwald 2005}

Fahrenwald NL, Atwood JR, Johnson DR. Mediator analysis of Moms on the move. Western Journal of Nursing Research 2005;27(3):271-91.

\section{Garrow 1995}

Garrow JS, Summerbell CD. Meta-analysis: effect of exercise, with or without dieting, on the body composition of overweight subjects. European Journal of Clinical Nutrition 1995;49(1):1-10.

\section{Gore 2003}

Gore SA, Brown DM, West DS. The role of postpartum weight retention in obesity among women: a review of the evidence. Annals of Behavioral Medicine 2003;26(2): 149-59.

\section{Greene 1988}

Greene GW, Smiciklas-Wright H, Scholl TO, Karp RJ. Postpartum weight change: how much of the weight gained in pregnancy will be lost after delivery?. Obstetrics \& Gynecology 1988;71(5):701-7.

\section{Gunderson 1999}

Gunderson EP, Abrams B. Epidemiology of gestational weight gain and body weight changes after pregnancy. Epidemiologic Reviews 1999;21(2):261-75.

\section{IOM 1990}

Institute of Medicine. Nutrition during pregnancy. Washington, DC: National Academy Press, 1990.

\section{IOM 1991}

Institute of Medicine. Nutrition during lactation. Washington, DC: National Academy Press, 1991.

Kac 2003

Kac G, D’Aquino Benicio MH, Valente JG, VelasquezMelendez G. Postpartum weight retention among women in Rio de Janeiro: a follow-up study. Reports in Public Health 2003;19(1 Suppl):149S-161S.

\section{Keppel 1993}

Keppel KG, Taffel SM. Pregnancy-related weight gain and retention: implications of the 1990 Institute of Medicine Guidelines. American Journal of Public Health 1993;83(8): $1100-3$.

\section{Linne 2002}

Linne Y, Barkeling B, Rossner S. Long-term weight development after pregnancy. Obesity Reviews 2002;3(2): $75-83$.

\section{Linne 2003a}

Linne Y, Rossner S. Easy to remain overweight after pregnancy. Lakartidningen 2003;100(49):4091-5.

\section{Linne 2003b}

Linne Y, Dye L, Barkeling B, Rossner S. Weight development over time in parous women--the SPAWN study--15 years follow-up. International Journal of Obesity and Related Metabolic Disorder 2003;27:1516-22.

\section{Linne 2003c}

Linne Y, Rossner S. Interrelationship between weight development and weight retention in subsequent pregnancies: the SPAWN study. Acta Obstetricia et Gynecologica Scandinavica 2003;82(4):318-25.

\section{Linne 2004}

Linne Y. Effects of obesity on women's reproduction and complications during pregnancy. Obesity Reviews 2004;5 (3):137-43.

\section{Lovelady 1995}

Lovelady CA, Nommsen-Rivers LA, McCrory MA, Dewey KG. Effects of exercise on plasma lipids and metabolism of lactating women. Medicine \& Science in Sports \& Exercise 1995;27(1):22-8

\section{Lovelady 2001}

Lovelady CA, Williams JP, Garner KE, Moreno KL, Taylor $\mathrm{Ml}$, Leklem JE. Effect of energy restriction and exercise on vitamin B-6 status of women during lactation. Medicine \& Science in Sports \& Exercise 2001;33(4):512-8.

\section{Lovelady 2006}

Lovelady CA, Stephenson KG, Kuppler KM, Williams JP. The effects of dieting on food and nutrient intake of lactating women. Journal of the American Dietetic Association 2006;106(6):908-12.

Manson 1990

Manson JE. A prospective study of obesity and risk of coronary heart disease in women. New England Journal of Medicine 1990;322(13):882-9.

\section{Mestecky 1986}

Mestecky J, Russell MW, Jackson S, Brown TA. The human IgA system: a reassessment. Clinical Immunology and Immunopathology 1986;40(1):105-14.

\section{Mottola 2002}

Mottola MF. Exercise in the postpartum period: practical applications. Current Sports Medicine Reports 2002;1(6): 362-8.

\section{Mukherjea 2000}

Mukherjea R, Moser-Veillon P, Lovelady C. Effect of exercise and energy restriction on leptin during lactation. 
Advances in Experimental Medicine and Biology 2000;478:

$417-8$.

Ohlin 1990

Ohlin A, Rossner S. Maternal body weight development after pregnancy. International Journal of Obesity 1990;14(2): 159-73.

\section{Olson 2003}

Olson CM, Strawderman MS, Hinton PS, Pearson TA. Gestational weight gain and postpartum behaviors associated with weight change from early pregnancy to $1 \mathrm{y}$ postpartum. International Journal of Obesity and Related Metabolic Disorders 2003;27(1):117-27. [MEDLINE: 12532163]

\section{Prentice 1994}

Prentice AM, Goldberg GR, Prentice A. Body mass index and lactation performance. European Journal of Clinical Nutrition 1994;48(3 Suppl):78S-86S.

\section{RevMan 2003}

The Cochrane Collaboration. Review Manager (RevMan). 4.2 for Windows. Oxford, England: The Cochrane Collaboration, 2003.

\section{Rooney 2002}

Rooney BL, Schauberger CW. Excess pregnancy weight gain and long-term obesity: one decade later. Obstetrics \& Gynecology 2002;100(2):245-52.

\section{Rossner 1992}

Rossner S. Pregnancy, weight cycling and weight gain in obesity. International Journal of Obesity and Related Metabolic Disorders 1992;16(2):145-7.

\section{Rossner 1995}

Rossner S, Ohlin A. Pregnancy as a risk factor for obesity: lessons from the Stockholm Pregnancy and Weight
Development Study. Obesity Research 1995;3(2 Suppl): 267S-275S.

\section{Sadurkis 1988}

Sadurkis A, Kabir N, Wager J, Forsum E. Energy metabolism, body composition and milk production in healthy Swedish women during lactation. American Journal of Clinical Nutrition 1988;48(1):44-9.

\section{Schauberger 1992}

Schauberger CW, Rooney BL, Brimer LM. Factors that influence weight loss in the puerperium. Obstetrics \& Gynecology 1992;79(3):424-9.

\section{Strode 1986}

Strode MA, Dewey KG, Lonnerdal B. Effects of shortterm caloric restriction on lactational performance of wellnourished women. Acta Paediatrica Scandinavica 1986;75 (2):222-9.

\section{Symons Downs 2004}

Symons Downs D, Hausenblas HA. Women's exercise beliefs and behaviors during their pregnancy and postpartum. American College of Nurse-Midwives 2004;49(2):138-44.

\section{WHO 1991}

World Health Organization. Indicators for assessing breastfeeding practices. Report of an informal meeting. Geneva: WHO, 1991.

\section{WHO 1998}

World Health Organization. Obesity: preventing and managing the global epidemic. Report of a WHO Consultation on Obesity. Geneva: WHO, 1998.

\section{Wood 2004}

Wood S, Hildebrandt LA. Use of low-carbohydrate diets during lactation. Implications for mothers and infants. Topics in Clinical Nutrition 2004;19(4):286-96.

* Indicates the major publication for the study 


\title{
CHARACTERISTICS OF STUDIES
}

\section{Characteristics of included studies [ordered by study ID]}

\author{
Armstrong 2003
}

Methods

Intervention was randomly assigned. The procedure was based on a 4-block randomised sequence (information not published). Allocation using sealed opaque envelopes.

Completeness of follow up (A), blinding of outcome assessment (C) and final classification (C)

\begin{tabular}{ll}
\hline Participants & $\begin{array}{l}20 \text { women who had a child between the ages of } 6 \text { weeks and } 12 \text { months and were experiencing depressive } \\
\text { symptomatology }\end{array}$
\end{tabular}

Interventions

Intervention: social support and aerobic exercise. The exercise programme consisted of supervised pram walking group sessions 3 times per week for 30-40 minutes at an intensity of 60-75\% of age-predicted heart rate for 12 weeks. Control: the control group were not involved in the multi-intervention programme.

Trial duration: medium-term.

\begin{tabular}{ll} 
Outcomes & VO2 max and adherence to intervention. \\
\hline Notes & $\begin{array}{l}\text { Data suggested good follow up (no drop outs) and no differences between groups at baseline. A total of } 36 \\
\text { exercise sessions were offered and the mean number of sessions attended was } 23.7 \text { (66\% of adherence) }\end{array}$
\end{tabular}

Risk of bias

\begin{tabular}{lll}
\hline Bias & Authors' judgement & Support for judgement \\
\hline Allocation concealment & Low risk & A - Adequate \\
\hline
\end{tabular}

\section{Dewey 1994a}

\begin{tabular}{ll} 
Methods & $\begin{array}{l}\text { Randomisation using a random-number table. Allocation using sealed, opaque envelopes (information not } \\
\text { published). } \\
\text { Completeness of follow up (A), blinding of outcome assessment (C) and final classification (C) }\end{array}$ \\
\hline Participants & 33 sedentary, nonsmoking women, without chronic disease, whose infants were being exclusively breastfed \\
\hline Interventions & $\begin{array}{l}\text { Intervention: } 45 \text { minutes of supervised aerobic exercise session at an intensity of } 60-70 \% \text { of maximal heart } \\
\text { rate reserve, } 5 \text { times per week for } 12 \text { weeks, beginning at } 6-8 \text { weeks postpartum. } \\
\text { Control: no regular aerobic exercise during the same time period. } \\
\text { Trial duration: medium-term. }\end{array}$ \\
\hline Outcomes & $\begin{array}{l}\text { Postpartum weight loss, body fat, fat-free mass, VO2 max, milk volume, infant weight gain and plasma } \\
\text { prolactin concentration }\end{array}$ \\
\hline Notes & $\begin{array}{l}\text { A total of } 38 \text { women enrolled in the study. } 5 \text { women did not complete the study (4 in the control group) } \\
\text { These women had similar characteristics to those who remained, however their infants had significantly } \\
\text { lower birthweights. There was a higher proportion of female infants in the exercise group (65\%) than } \\
\text { in control (46\%). Women in the exercise group reported significantly higher energy intakes than control }\end{array}$
\end{tabular}

Diet or exercise, or both, for weight reduction in women after childbirth (Review)

Copyright () 2012 The Cochrane Collaboration. Published by John Wiley \& Sons, Ltd. 


\section{Dewey 1994a (Continued)}

subjects at baseline. All subjects were able to exclusively breastfeed their infants during the study period. Research assistants visited the homes at each exercise session to assure compliance. Data concerning fat free mass were extracted from Lovelady et al, 1995

\section{Risk of bias}

\begin{tabular}{lll} 
Bias & Authors' judgement & Support for judgement \\
\hline Allocation concealment & Low risk & A - Adequate \\
\hline
\end{tabular}

Leermakers 1998

Methods

Randomisation stated, but method not reported.

Completeness of follow up (C), blinding of outcome assessment (B) and final classification (C)

Participants

62 women who had given birth in the past 3-12 months and whose weight exceed their prepregnancy weight by at least $6.8 \mathrm{~kg}$. Women who were breastfeeding their infant were excluded from the study

Interventions

Intervention: 2 group sessions, held at the beginning of intervention and at month 2 . Women were instructed in the group sessions to follow a diet of 1000-1500 kcal per day, begin an aerobic programme and self-monitor. Correspondence material consisted of 16 lessons focused on low-fat and low-caloric eating habits and increasing physical activity, delivered over 6 months. Telephone contacts were made weekly or biweekly, depending on participants request during 6 month intervention period.

Control: the control group did not receive any treatment, but participants were given an informational brochure about healthy eating and exercise.

Trial duration: medium-term

Outcomes

Postpartum weight loss, percentage of women who returned to prepregnancy weight and adherence to intervention

Notes

A total of 90 women enrolled in the study. 28 women dropped out of the study (11 in the intervention group and 17 in the control). The drop-outs were significantly heavier at baseline and retained significantly more weight after pregnancy than completers.

The intervention group was significantly older and had a greater percentage of married women, compared to control group.

Women returned 10.1 self-monitoring records ( $40.4 \%$ of adherence) and 7.6 homework assignments (50.

$7 \%$ of adherence). They received an average of 10.3 telephone contacts during the 6 -month programme

Risk of bias

\begin{tabular}{l|l|l}
\hline Bias & Authors' judgement & Support for judgement \\
\hline Allocation concealment & Unclear risk & B - Unclear \\
\hline
\end{tabular}

Diet or exercise, or both, for weight reduction in women after childbirth (Review) 


\begin{tabular}{|c|c|}
\hline Methods & $\begin{array}{l}\text { Women were randomly assigned using a random-number table, after stratification according to the sex } \\
\text { of their infants. Allocation using sealed, opaque envelopes. Completeness of follow up (A), blinding of } \\
\text { outcome assessment (C) and final classification (C) }\end{array}$ \\
\hline Participants & $\begin{array}{l}40 \text { healthy, sedentary, nonsmoking and exclusively breastfeeding women, who were overweight at } 4 \text { weeks' } \\
\text { postpartum and had delivered a full-term infant weighing at least } 2500 \mathrm{~g} \text { and had not delivered by caesarean } \\
\text { section }\end{array}$ \\
\hline Interventions & $\begin{array}{l}\text { Intervention: restriction of } 500 \mathrm{kcal} \text { from the average of reported daily energy intake and estimated energy } \\
\text { requirements. } 45 \text { minutes of supervised aerobic exercise } 4 \text { times per week at an intensity of } 65-80 \% \text { of } \\
\text { maximal heart rate reserve for } 10 \text { weeks, beginning at } 4 \text { weeks postpartum. Control: usual dietary intake } \\
\text { and not exercise more than once per week for } 10 \text { weeks. All women were given a multivitamin supplement } \\
\text { containing at least } 50 \% \text { of the recommended dietary allowances for lactating women. } \\
\text { Trial duration: short-term. }\end{array}$ \\
\hline Outcomes & $\begin{array}{l}\text { Postpartum weight loss, percentage of women who achieved a BMI below } 25 \text {, percentage of women who } \\
\text { were within } 1 \mathrm{~kg} \text { of their prepregnancy weight, body fat, fat-free mass, VO2 max, infant weight gain and } \\
\text { infant length gain }\end{array}$ \\
\hline Notes & $\begin{array}{l}\text { A total of } 48 \text { women enrolled in the study. } 8 \text { women dropped out of the study ( } 6 \text { in the intervention group } \\
\text { and } 2 \text { in the control). The drop outs were significantly heavier before pregnancy; tend to have higher BMI } \\
\text { and heavier infants at birth and lower level of cardiovascular fitness compared to women who complete the } \\
\text { study. Research assistants visited the homes at each exercise session to assure compliance. All participants, } \\
\text { but } 1 \text { were able to exercise } 4 \text { days per week }\end{array}$ \\
\hline
\end{tabular}

\section{Risk of bias}

\begin{tabular}{l|l|l}
\hline Bias & Authors' judgement & Support for judgement \\
\hline Allocation concealment & Low risk & A - Adequate \\
\hline
\end{tabular}

\section{McCrory 1999}

Methods Random assignment of participants was computer-based using Moses-Oakford algorithm with variables block size.

Completeness of follow up (A), blinding of outcome assessment $(\mathrm{C})$ and final classification (C)

Participants

67 nonsmoking, exclusively breastfeeding women, who had no chronic illnesses, were not taking medication regularly and had delivered a single healthy, term infant.

Participants were randomised at 8-16 weeks' postpartum.

Interventions

Intervention I: diet group - 35\% of energy deficit for 11 days. Intervention II: diet plus exercise group $35 \%$ of net energy deficit for 11 days ( $60 \%$ by dietary restriction and $40 \%$ by additional exercise). Women in this group performed aerobic exercises during 86 minutes per session at an intensity of $50-70 \%$ of maximal heart rate on 9 of the 11 days. Exercise sessions were self-supervised.

Control: no energy restriction and exercise.

Trial duration: short-term. 
McCrory 1999 (Continued)

\begin{tabular}{lll}
\hline Outcomes & Postpartum weight loss, body fat, fat-free mass, milk volume and plasma prolactin concentration \\
\hline Notes & $\begin{array}{l}\text { 2 of } 68 \text { participants enrolled discontinued study. Both were assigned to the diet plus exercise group. 1 } \\
\text { withdrew after assignment, but before the beginning of intervention. The other did not continue with the } \\
\text { intervention after day 8. Data for the latter participant were included in the analysis. } \\
\text { Data suggested good compliance with the intervention. }\end{array}$ \\
\hline Risk of bias & Authors' judgement & Support for judgement \\
\hline Bias & Low risk & A - Adequate \\
\hline Allocation concealment
\end{tabular}

\section{O’Toole 2003}

\begin{tabular}{ll} 
Methods & $\begin{array}{l}\text { Interventions were randomly assigned, but method not reported. Allocation using blinded drawing of } \\
\text { labels containing group assignment. } \\
\text { Completeness of follow up (C), blinding of outcome assessment (B) and final classification (C) }\end{array}$ \\
\hline Participants & $\begin{array}{l}23 \text { postpartum women, who were overweight prior to pregnancy, had gained more than } 15 \mathrm{~kg} \text { during } \\
\text { pregnancy and were more than } 5 \mathrm{~kg} \text { heavier than prepregnancy at the time of enrolment. Participants were } \\
\text { randomised between } 6 \text { weeks' and } 6 \text { months' postpartum }\end{array}$ \\
\hline Interventions & $\begin{array}{l}\text { Intervention I: structured diet and physical activity group, which included individualised diet prescriptions } \\
\text { derived from baseline measurements, daily food and activity diaries, healthy cooking demonstration. }\end{array}$ \\
$\begin{array}{l}\text { A specific, individualised activity plan consisting of moderate intensity activity and guided by heart rate } \\
\text { was developed for each participant. } \\
\text { The intervention also included educational group sessions held once a week for } 12 \text { weeks, biweekly for } \\
\text { the following } 2 \text { months, and monthly up to } 1 \text { year postpartum. Intervention II: self-directed group based } \\
\text { on general advice about diet and exercise. This group participated in a single 1-hour educational session } \\
\text { about healthy diet and exercise practices. Participants were given some brochures about nutrition and food } \\
\text { guide pyramid. } \\
\text { Trial duration: long-term. }\end{array}$ \\
\hline
\end{tabular}

Outcomes

Postpartum weight loss, percentage of women who achieved a BMI below 25, body fat, fat-free mass (values not available) and VO2 max
Notes
40 women enrolled in the study, but 23 remained up to 1 year postpartum ( $58 \%$ of retention). There were no differences between those who finished the study and those who dropped out.
Percentage of body fat was significantly higher in the self-directed group than in the structured group at baseline

\section{Risk of bias}

\begin{tabular}{lll}
\hline Bias & Authors' judgement & Support for judgement \\
\hline Allocation concealment & Low risk & A - Adequate \\
\hline
\end{tabular}

Diet or exercise, or both, for weight reduction in women after childbirth (Review)

Copyright () 2012 The Cochrane Collaboration. Published by John Wiley \& Sons, Ltd. 
BMI: body mass index

Characteristics of excluded studies [ordered by study ID]

\begin{tabular}{l|l}
\hline Study & Reason for exclusion \\
\hline Armstrong 2004 & 1. Inclusion of women over 12 months postpartum. \\
\hline Bopp 2005 & $\begin{array}{l}\text { 1. Nonclinical trial. The participants were grouped according to their exercise habits into exercise or sedentary } \\
\text { group. The experimental part of the study consisted of returning, of a subsample of exercise group, to the } \\
\text { laboratory } 2 \text { additional times for rest and exercise sessions. } \\
\text { 2. The experimental part of the study did not intend to create a caloric deficit for weight control, improve } \\
\text { cardiorespiratory fitness or encourage women to increase their physical activity level }\end{array}$ \\
\hline
\end{tabular}

Carey 1997 1. The intervention did not intend to create a caloric deficit for weight control, improve cardiorespiratory fitness or encourage women to increase their physical activity level. The intervention consisted of only 4 laboratory visits to perform exercise at $100 \%, 50 \%$ and $70 \%$ of VO2max and nonexercise control session to determine if breastmilk composition changed following exercise conducted at different intensities.

2. The study did not involve sedentary women as a control group. Every woman served as both an exercising volunteer and a nonexercising control subject during the rest session

Duckman 1968 1. Intervention for postpartum weight control involved medication

Fahrenwald 2004 1. Inclusion of women over 12 months postpartum and younger than 18 year of age

Fly 1998 1. The intervention did not intend to create a caloric deficit for weight control, improve cardiorespiratory fitness or encourage women to increase their physical activity level. The intervention consisted of 2 laboratory visits for a maximal graded exercise test and resting control period.

2. The study did not involve sedentary women as a control group. Every woman served as both an exercising volunteer and a nonexercising control subject during the rest session on different days

Gregory 1997 1. The intervention did not intend to create a caloric deficit for weight control, improve cardiorespiratory fitness or encourage women to increase their physical activity level.

2. The study did not involve sedentary women as a control group. Every woman served as both an exercising volunteer and a nonexercising control subject on different days

Koltyn $1997 \quad$ 1. Did not assess any outcome of interest.

Krummel 2004 1. Cross-sectional data collected at baseline, of “Mother's Overweight Management Study," a randomised controlled trial for weight gain prevention.

2. Inclusion of women over 12 months postpartum.

Lovelady 2003 1. Nonclinical trial. The participants were grouped according to their exercise habits into exercise or sedentary group. The experimental part of the study consisted of returning, of a subsample of exercise group, to the laboratory 2 additional times for rest and exercise sessions.

2. The experimental part of the study did not intend to create a caloric deficit for weight control, improve cardiorespiratory fitness or encourage women to increase their physical activity level

Diet or exercise, or both, for weight reduction in women after childbirth (Review) 
(Continued)

Ostbye 2003 1. Nonintervention study. The purpose of this study was to better understand the attitudes and preferences for weight loss among postpartum women.

2. The study refers to a planned trial. It is stated in the article that an intervention study is being designed; however no more information was provided

Quinn 1999 1. The comparison groups (high carbohydrate diet plus exercise versus moderate carbohydrate diet plus exercise) are not included in this review.

2. Dietary intervention involved no change in energy intake or dietary advice for weight reduction.

3. Exercise intervention did not intend to create a caloric deficit for weight control, improve cardiorespiratory fitness or encourage women to increase their physical activity level. The exercise programme consisted of 4 laboratory visits: 1 for maximal graded exercise test, 2 exercise sessions at different intensities and 1 rest session

Wallace 1991 1. The intervention did not intent to create a caloric deficit for weight control, improve cardiorespiratory fitness or encourage women to increase their physical activity level. The intervention consisted of a maximal graded exercise test.

2. The study did not involve sedentary women as a control group. Every woman was assigned to an exercise test.

The study compared data from pre-exercise rest, exercise test and postexercise period.

3. Inclusion of women who had delivery over 12 months.

Wallace 1992a 1. The intervention did not intend to create a caloric deficit for weight control, improve cardiorespiratory fitness or encourage women to increase their physical activity level. The intervention consisted of a maximal graded exercise test. The women were randomly assigned to group $\mathrm{E}$ which nursed prior to maximal exercise test and group $\mathrm{F}$ which did not nurse.

2. The study did not involve sedentary women as a control group. Every woman was assigned to exercise test

Wallace 1992b 1. The intervention did not intend to create a caloric deficit for weight control, improve cardiorespiratory fitness or encourage women to increase their physical activity level. The intervention consisted of a maximal graded exercise test to assess the infant acceptance of postexercise breastmilk.

2. The study did not involve sedentary women as a control group. Every woman was assigned to exercise test

Wright 2002 1. The intervention did not intend to create a caloric deficit for weight control, improve cardiorespiratory fitness or encourage women to increase their physical activity level. The intervention consisted of 4 laboratory visits: 1 for instructions, 2 for performing a maximal intensity and moderate exercise test, respectively and 1 rest session.

2. The study did not involve sedentary women as a control group. Every woman served as both an exercising volunteer and a nonexercising control subject during the rest period on different days

\section{Characteristics of ongoing studies [ordered by study ID]}

\section{Peterson 2002}

Trial name or title Enhanced Expanded Food and Nutrition Education Program (EFNEP)

Methods

Participants $\quad 700$ postpartum women from 2 urban areas who are WIC eligible

Diet or exercise, or both, for weight reduction in women after childbirth (Review) 
Peterson 2002 (Continued)

\begin{tabular}{ll}
\hline Interventions & $\begin{array}{l}\text { Participants are } \\
\text { randomised to the usual WIC care or Enhanced } \\
\text { EFNEP intervention arm. } \\
\text { The usual WIC care consists of nutrition education and breastfeeding consultation at the first postpartum } \\
\text { and follow-up visits up to } 12 \text { months from delivery. } \\
\text { The Enhanced } \\
\text { EFNEP intervention consists of usual } \\
\text { WIC care plus a sustained, multi-component } \\
\text { intervention including home visits, group classes } \\
\text { and monthly telephone counseling in the first } 12 \text { months postpartum and } \\
\text { after } 6 \text { months of maintenance. The purpose of the study is to test the efficacy of an educational model in } \\
\text { improving diet, activity and weight loss among new mothers }\end{array}$ \\
\hline Outcomes & $\begin{array}{l}\text { BMI, fat mass and body fat distribution. } \\
\text { Starting date }\end{array}$ \\
\hline Contact information & $\begin{array}{l}\text { Peterson KE, } \\
\text { Departments of Maternal and Child Health, and } \\
\text { Nutrition, Harvard School of Public Health, Boston, MA - USA }\end{array}$ \\
\hline Notes & \\
\hline
\end{tabular}

BMI: body mass index 
DATA AND ANALYSES

Comparison 1. Diet versus usual care

\begin{tabular}{|c|c|c|c|c|}
\hline Outcome or subgroup title & $\begin{array}{l}\text { No. of } \\
\text { studies }\end{array}$ & $\begin{array}{c}\text { No. of } \\
\text { participants }\end{array}$ & Statistical method & Effect size \\
\hline 1 Change in body weight $(\mathrm{kg})$ & 1 & 45 & Mean Difference (IV, Fixed, 95\% CI) & $-1.7[-2.08,-1.32]$ \\
\hline 2 Change in $\%$ body fat & 1 & 45 & Mean Difference (IV, Fixed, 95\% CI) & $-0.40[-1.15,0.35]$ \\
\hline 3 Change in fat-free mass $(\mathrm{kg})$ & 1 & 45 & Mean Difference (IV, Fixed, 95\% CI) & $-0.90[-1.38,-0.42]$ \\
\hline $\begin{array}{l}4 \text { Change in basal plasma prolactin } \\
\text { concentration }(\mu \mathrm{g} / \mathrm{mL})\end{array}$ & 1 & 45 & Mean Difference (IV, Fixed, 95\% CI) & $2.24[-13.95,18.43]$ \\
\hline 5 Change in milk volume (g/day) & 1 & 45 & Mean Difference (IV, Fixed, 95\% CI) & $\begin{array}{l}-18.0[-63.87,27 . \\
87]\end{array}$ \\
\hline
\end{tabular}

\section{Comparison 2. Exercise versus usual care}

\begin{tabular}{|c|c|c|c|c|}
\hline Outcome or subgroup title & $\begin{array}{l}\text { No. of } \\
\text { studies }\end{array}$ & $\begin{array}{c}\text { No. of } \\
\text { participants }\end{array}$ & Statistical method & Effect size \\
\hline 1 Change in body weight $(\mathrm{kg})$ & 1 & 33 & Mean Difference (IV, Fixed, 95\% CI) & $0.0[-8.63,8.63]$ \\
\hline 2 Change in $\%$ body fat & 1 & 33 & Mean Difference (IV, Fixed, 95\% CI) & $0.20[-5.40,5.80]$ \\
\hline 3 Change in fat-free mass $(\mathrm{kg})$ & 1 & 33 & Mean Difference (IV, Fixed, 95\% CI) & $0.30[-3.78,4.38]$ \\
\hline $\begin{array}{l}4 \text { Change in VO2max } \\
(\mathrm{mL} / \mathrm{kg} / \text { minute })\end{array}$ & 2 & 53 & Mean Difference (IV, Fixed, 95\% CI) & $7.08[4.03,10.13]$ \\
\hline $\begin{array}{l}5 \text { Change in basal plasma prolactin } \\
\text { concentration }(\mu \mathrm{g} / \mathrm{mL})\end{array}$ & 1 & 33 & Mean Difference (IV, Fixed, 95\% CI) & $\begin{array}{l}-6.73[-54.62,41 . \\
16]\end{array}$ \\
\hline 6 Change in milk volume (g/day) & 1 & 33 & Mean Difference (IV, Fixed, 95\% CI) & $\begin{array}{l}40.0[-109.16,189 . \\
16]\end{array}$ \\
\hline 7 Infant weight gain $(\mathrm{g})$ & 1 & 33 & Mean Difference (IV, Fixed, 95\% CI) & $\begin{array}{l}26.17[-756.15,808 . \\
49]\end{array}$ \\
\hline
\end{tabular}

Comparison 3. Diet plus exercise versus usual care

\begin{tabular}{|c|c|c|c|c|}
\hline Outcome or subgroup title & $\begin{array}{l}\text { No. of } \\
\text { studies }\end{array}$ & $\begin{array}{c}\text { No. of } \\
\text { participants }\end{array}$ & Statistical method & Effect size \\
\hline 1 Change in body weight (kg) & 4 & & Mean Difference (IV, Random, 95\% CI) & Subtotals only \\
\hline 1.1 All studies & 4 & 169 & Mean Difference (IV, Random, 95\% CI) & $-2.89[-4.83,-0.95]$ \\
\hline $\begin{array}{l}1.2 \text { Subcategory: dietary } \\
\text { advice and exercise counselling }\end{array}$ & 1 & 62 & Mean Difference (IV, Random, 95\% CI) & $-2.90[-5.44,-0.36]$ \\
\hline $\begin{array}{l}1.3 \text { Subcategory: caloric } \\
\text { restriction and structured } \\
\text { exercise programme }\end{array}$ & 3 & 107 & Mean Difference (IV, Random, 95\% CI) & $-2.94[-5.37,-0.52]$ \\
\hline
\end{tabular}

Diet or exercise, or both, for weight reduction in women after childbirth (Review)

Copyright @ 2012 The Cochrane Collaboration. Published by John Wiley \& Sons, Ltd. 